\title{
STEM-EELS Investigation of Planar Defects in Olivine in the Allende Meteorite
}

\author{
Maya Marinova ${ }^{1, *}$, Hugues Leroux ${ }^{2, *}$, Priscille Cuvillier ${ }^{2,+}$, Alexandre Gloter ${ }^{3} \mathbb{D}$ and Damien Jacob ${ }^{2} \mathbb{D}$ \\ 1 Univ. Lille, CNRS, INRAE, Centrale Lille, Univ. Artois, FR 2638-IMEC-Institut Michel-Eugène Chevreul, \\ F-59000 Lille, France \\ 2 Univ. Lille, CNRS, INRAE, Centrale Lille, UMR 8207-UMET-Unité Matériaux et Transformations, \\ F-59000 Lille, France; priscille.cuvillier@edf.fr (P.C.); damien.jacob@univ-lille.fr (D.J.) \\ 3 Université Paris-Saclay, CNRS UMR 8502, Laboratoire de Physique des Solides (LPS), 91405 Orsay, France; \\ alexandre.gloter@universite-paris-saclay.fr \\ * Correspondence: maya.marinova@univ-lille.fr (M.M.); hugues.leroux@univ-lille.fr (H.L.) \\ + Present affiliation: EDF-Industrial Direction, NPP of Chinon-BP23, 37420 Avoine, France.
}

check for updates

Citation: Marinova, M.; Leroux, H.; Cuvillier, P.; Gloter, A.; Jacob, D. STEM-EELS Investigation of Planar Defects in Olivine in the Allende Meteorite. Minerals 2021, 11, 35. https://doi.org/10.3390/min11010035

Received: 4 December 2020 Accepted: 22 December 2020 Published: 30 December 2020

Publisher's Note: MDPI stays neutral with regard to jurisdictional clai$\mathrm{ms}$ in published maps and institutional affiliations.

Copyright: (C) 2020 by the authors. Licensee MDPI, Basel, Switzerland. This article is an open access article distributed under the terms and conditions of the Creative Commons Attribution (CC BY) license (https:// creativecommons.org/licenses/by/ $4.0 /)$.

\begin{abstract}
The present study focuses on a detailed structural investigation at atomic scale of the planar defects that appear in the olivine grains in the Allende meteorite, and it aims to clarify their nature and the related formation mechanism. The investigation was performed using advanced spectromicroscopy techniques such as atomically resolved high-angle annular dark field (HAADF) images coupled with electron energy loss spectroscopy in the scanning transmission electron microscopy mode (STEM-EELS). Two prominent structural features appear in the investigated olivine grains: (i) Exsolution platelets with a thickness between 2 and $10 \mathrm{~nm}$ with the spinel structure and chemical composition expressed as a solid solution between magnetite, chromite, and $\mathrm{MgAl}_{2} \mathrm{O}_{4}$. (ii) Thinner planar defects appeared with thickness between 2 to 4 atomic planes, which were rich in Fe and had a strong $\mathrm{Fe}^{3+}$ contribution. The structure of these defects was described by the crystalline lattice of the olivine grains with small distortion of the measured cationic distances, which can be related to $\mathrm{Fe}^{3+}-\mathrm{Si}$ substitution in the tetrahedral sites. Those metastable defects should have preceded the formation of the thicker spinel exsolutions and could have formed during an oxidizing event in the Allende parent body.
\end{abstract}

Keywords: STEM-EELS; HAADF; olivine; Allende; planar defects

\section{Introduction}

The CV type chondrites are carbonaceous chondrites, which have experienced some level of aqueous alteration and thermal metamorphism during their history. They contain large-sized chondrules and refractory inclusions, cemented by a fine-grained matrix dominated by anhydrous silicates. The dominant phase of this matrix is a FeO-rich olivine (typically between $\mathrm{Fa}_{50}$ and $\mathrm{Fa}_{60}$, corresponding to a composition range $\mathrm{Fe}_{1.0-1.2} \mathrm{Mg}_{1.0-0.8} \mathrm{SiO}_{4}$ ), whose origin has been the subject of debates. The proposed scenarios, which are still under discussion, include a formation in a nebular environment before accretion [1,2] or secondary processes on the parent body [3,4].

The olivine grains in the matrices of $\mathrm{CV}$ chondrites are typically micron-sized with frequent elongated shapes, described as platy, tubular, or lath-shaped crystals $[1,4,5]$. The elongated grains have their short axis along the $a$ crystallographic direction (with the olivine Pbnm space group), leading to an alignment fabric of the matrix during lithification $[5,6]$. Transmission electron microscopy (TEM) studies showed that the olivine grains contain numerous nanometer-sized voids and inclusions [7-9], mainly composed of hercynitic spinel, carbonaceous matter and sulfides. Moreover, several studies carried out by TEM have shown that the olivine grains of $\mathrm{CV}$ chondrites frequently contain planar defects parallel to either (100) or (001) planes [8,10-14]. 
The crystalline defects contained in olivine are certainly useful for better understanding the olivine formation itself as well as the thermal or mechanical events underwent after their formation, during or after the parent body metamorphic episode. This information is valuable for contributing to a better understanding of the physical and chemical conditions that prevailed on the parent body of $\mathrm{CV}$-chondrite. The results reported here are focused on the study of planar defects which are present in abundance in the olivine of CV chondrites, whereas they are rather unusual in other asteroidal contexts. To characterize these defects at the atomic scale, olivine grains extracted from the matrix of the Allende CV chondrite were studied using high-resolution scanning transmission electron microscopy (STEM) imaging and electron energy loss spectroscopy (EELS). We then propose a mechanism of formation of these defects and discuss their significance in a context of the metamorphic stage of the chondrite parent body.

\section{Materials and Methods}

The thin foils were extracted from the Allende matrix by focused ion been (FIB) at IEMN, University of Lille. The FIB was performed using a dual-beam Thermo-Fisher Strata DB235 workstation. The electron beam source is a field emission gun and for the ion beam source, a liquid/metal gallium was used. Before the thin foil extraction, the selected areas from the Allende meteorite were covered with Pt for protection. For the first part of the extraction, a beam current of about $10 \mathrm{nA}$ at $15 \mathrm{kV}$ was used, and for the final thinning, a beam current of approximately $50 \mathrm{pA}$ at $5 \mathrm{kV}$ was used in order to minimize amorphization, redeposition, and obtain homogeneous thickness of the studied regions, therefore allowing high-resolution high-angle annular dark field (HAADF) imaging and STEM-EELS analysis. The STEM observations were performed on a dedicated Cs-corrected NION UltraSTEM200 at LPS Orsay for the EELS part and a Thermo-Fisher Titan Themis S/TEM at the microscopy platform of the University of Lille for part of the HAADF imaging and the Energy-dispersive X-ray (EDX) mapping. The UltraSTEM200 is equipped with a cold-field emission electron source operating at $100 \mathrm{kV}$ with a probe size of $1 \AA$ and energy resolution of $350 \mathrm{meV}$ in the core-loss region, allowing for an atomic resolution imaging coupled to high energy resolution EELS for fine structure analysis. The TITAN Themis $\mathrm{S} / \mathrm{TEM}$ is equipped with a high brightness Schottky field emission gun and monochromator. The EELS measurements were performed with a collection semi-angle of $50 \mathrm{mrad}$ for achieving STEM-EELS investigations with high spatial resolution. A probe convergence semi-angle of $30 \mathrm{mrad}$ was selected for high-resolution HAADF imaging. The probe current was approximately $80 \mathrm{pA}$. The EELS spectra were acquired using the spectrum line and spectrum imaging modes, with an energy dispersion of 0.125 to $0.65 \mathrm{eV} /$ channel and an acquisition time from a few $\mathrm{ms}$ to $1 \mathrm{~s}$. Energy dispersions of $0.125 \mathrm{eV} / \mathrm{channel}$ were used for the energy loss near edge structures (ELNES) spectra and $0.65 \mathrm{eV} /$ channel for chemical mapping. To minimize electron beam damage as much as possible, we worked using a spectrum imaging mode with a short dwell time per pixel (100 ms) and a beam current of about $80 \mathrm{pA}$. Under these conditions, we verified that no chemical shift or peak shape modification occurred, by testing different acquisition times, probe current, and high tensions. The HAADF images on the Titan Themis were acquired with a convergence semi-angle of $21 \mathrm{mrad}$ and a camera length allowing collection angles between 50 and $200 \mathrm{mrad}$. The probe current was selected between 50 and 80 pA. For the STEM-EDX mapping, a Thermo-Fisher super- $X$ windowless 4 quadrants silicon drift detection (SDD) was used.

\section{Results}

Figure 1 shows representative low magnification TEM and HAADF images of the olivine assemblage in the Allende matrix. The olivine grains have an elongated shape, suggesting a plate or needle morphology. The short axis is along the [100] direction. In the studied matrix area, the composition of the olivine is fairly homogeneous from grain to grain, with the $\mathrm{Fe} / \Sigma(\mathrm{Fe}+\mathrm{Mg})$ ratio close to $0.58\left(\mathrm{Fa}_{58}\right)$, and there is no chemical zoning 
inside the grains. Thin planar defects parallel to the (100) planes within the olivine grains are frequent. They appear with higher intensity in the HAADF images in Figure $1 \mathrm{c}, \mathrm{d}$, suggesting change in composition. Slightly thicker platelets were found locally at the edges of the olivine grain and, in this case, they were $\mathrm{Cr}$ enriched, as it can be seen from the STEMEDX maps presented in Figure 1e-h. As it can be seen from the HAADF images in Figure $1 \mathrm{c}, \mathrm{d}$, the olivine grains also contain numerous low- $\mathrm{Z}$ contrast inclusions (darker regions) consisting of Al-rich spinel, indicated with circles in the STEM-EDX map in Figure 1h, voids, and frequent $\mathrm{C}$-rich material.

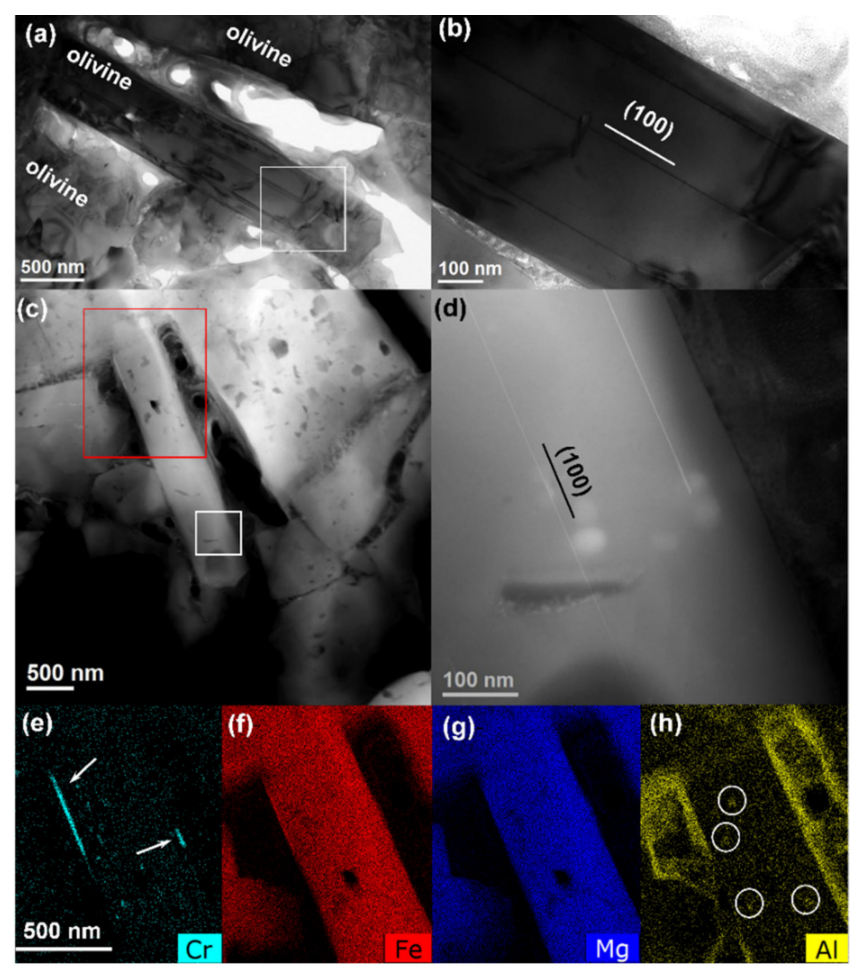

Figure 1. (a) Bright-field TEM image at low magnification showing olivine grains cemented by a poorly crystallized silicate groundmass. Note the elongated shape of the olivine grains. (b) Magnified view corresponding to the white rectangular box in (a). The olivine grains contain frequent thin planar defects parallel to the (100) planes. (c) HAADF image of an elongated olivine grain in the matrix. (d) HAADF magnified view according to the white rectangle in (c) showing that thin planar defects display high $\mathrm{Z}$ contrast. (e-h) STEM-EDX maps of respectively $\mathrm{Cr}, \mathrm{Fe}, \mathrm{Mg}$, and $\mathrm{Al}$ of the area marked by red rectangle in (c). The olivine contains numerous low- $Z$ contrast inclusions consisting of Al-rich spinel (indicated with circles in the EDX map in (h), voids, and frequent C-rich material. White arrows in (e) highlight Cr-rich thin platelets that locally cover the olivine edges.

Figure 2 shows typical high-resolution HAADF images of the olivine in the (010) projection where the two different planar features within the olivine are visible. Those two defects follow the (100) planes of olivine. Figure $2 \mathrm{~d}$ gives the crystallographic representation of the olivine in the same projection. Olivine has orthorhombic lattice (space group: Pbnm) with lattice parameters $a=4.78 \AA, b=10.34 \AA$, and $c=6.04 \AA$. A magnification of the area marked with a red rectangle in Figure $2 b$ is given in Figure 2c. On the HAADF images in the (010) projection, the brightest atomic columns of the olivine matrix, appearing as doublets along the a ([100]) axis, correspond to mixed columns comprising Si cations in tetrahedral positions and $\mathrm{Fe} / \mathrm{Mg}$ cations in the $\mathrm{M} 2$ octahedral position. The doublets with alternating column distances of 2.1 and $2.5 \AA$ appear as a function of the orientation of the Si tetrahedral along the $a$ axis and this is indicated by ellipses in Figure 2c,d. The less intense columns separated by a distance of $2.25 \AA$ correspond to mixed $\mathrm{Fe} / \mathrm{Mg}$ cations in the $M 1$ octahedral position. They alternate along the $c$ ([001]) axis with the atomic columns 
including the $\mathrm{Fe} / \mathrm{Mg}$ cations in the $\mathrm{M} 2$ octahedral position. Both planar defects appear along the $c([001])$ axis in the (100) planes.

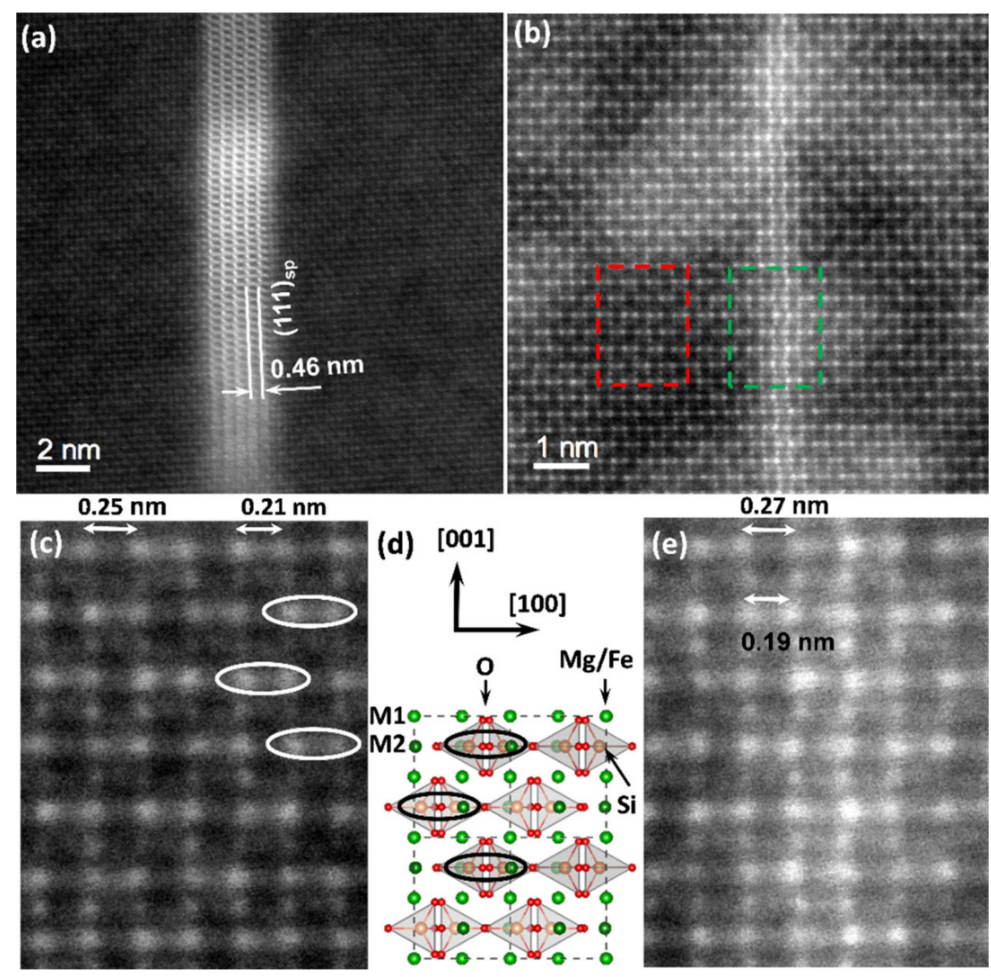

Figure 2. (a) HAADF image of thicker (100) platelets in olivine. (b) HAADF image of 4-atomicplanes-thick (100) planar defect in olivine (green dashed box). (c) Magnification of the olivine matrix in the area marked by the red dashed box in panel (b). In the HAADF image, the brighter columns correspond to a mixture of Si cations in tetrahedral position and $\mathrm{Fe} / \mathrm{Mg}$ cations in the $\mathrm{M} 2$ position. Along these atomic rows a doublet appears, depending on the orientation of the Si tetrahedra along the [100] axis, with short distances of $\sim 0.21 \mathrm{~nm}$ (marked by white ellipses) and longer distances of $\sim 0.25 \mathrm{~nm}$. The Fe/Mg cations in the $M 1$ position appear less intense and are separated by a distance of $\sim 0.225 \mathrm{~nm}$. They alternate along the [001] axis with the Fe/Mg cations in the M2 position. (d) The corresponding representation of the olivine crystal lattice in the (010) projection (orange is Si cation, red is $\mathrm{O}$ anion, green is $\mathrm{Mg} / \mathrm{Fe}$ cations in $\mathrm{M} 1$ or $\mathrm{M} 2$ positions). Si tetrahedra are marked in gray. (e) Magnification of the thin planar defect in the area marked by the green dashed box in panel (b). A change, by up to $\sim 20 \pm 7 \mathrm{pm}$, of the distances between the mixed atomic columns that include $\mathrm{Si}$ cations in tetrahedral positions and $\mathrm{Fe} / \mathrm{Mg}$ cations in the $\mathrm{M} 2$ octahedral positions is observed.

The defects such as the one observed in the HAADF image in Figure 2a correspond to platelets with thicknesses varying between 2 and $10 \mathrm{~nm}$ depending on the specific defect. Similar platelets were also seen in the HAADF image and the STEM-EDX maps in Figure 1c,e at the edge of the olivine grains (marked with white arrows in Figure 1e). These platelets correspond to exsolutions with the spinel structure. From the STEM-HAADF images and the comparison between the extracted fast Fourier transform patterns and simulated electron diffraction patterns, the orientation relationship was determined to correspond to [100]Ol | | $<111\rangle_{\mathrm{Sp}}$ and [001]Ol| | $\left.<110\right\rangle_{\mathrm{Sp}}$ with an interface plane $(100)_{\mathrm{Ol}}||\{111\}$ $\mathrm{Sp}$, which is in agreement with Sung et al. [15].

The thin defects occurring in Figure $2 \mathrm{~b}$ have thicknesses of 2 to 4 atomic planes. Within these thinner defects, the olivine crystal structure was preserved with only a small distortion of the atomic column positions in the inner atomic planes of the defect. These distortions mainly concern the [100] rows with the mixed atomic columns of Si cations in tetrahedral sites and $\mathrm{Fe} / \mathrm{Mg}$ cations in the $\mathrm{M} 2$ octahedral positions, and correspond to atomic column displacements up to $\sim 20 \pm 7 \mathrm{pm}$ averaged over 30 measurements. This distortion concerns 
a lengthening of the larger doublet distances (to $2.7 \AA$ ) and shortening of the smaller ones (to $1.9 \AA$ ), Figure 2e. In the HAADF image, the atomic column positions of the $\mathrm{Fe} / \mathrm{Mg}$ cations in the $M 1$ octahedral positions within the thin defect remained unchanged. These thinner defects were often connected to the thicker spinel platelets within the olivine. Both HAADF images reveal a clear increase in intensity of the HAADF signal over the thickness of these planar features, indicating a change in chemical composition.

In order to investigate in more detail the planar defects, STEM-EELS experiments were performed. Figure $3 \mathrm{a}-\mathrm{c}$ gives an online HAADF image of the thicker platelets, relative concentration profiles of the $\mathrm{Fe}-\mathrm{L}_{3,2}, \mathrm{Cr}-\mathrm{L}_{3,2}$, and Mg-K EELS edges, and the corresponding EELS spectra from the platelet and the matrix in the energy range between 500 and $1400 \mathrm{eV}$, which includes the $\mathrm{O}-\mathrm{K}$ edge $(530 \mathrm{eV}), \mathrm{Cr}-\mathrm{L}_{3,2}$ edge $(575 \mathrm{eV}), \mathrm{Fe}-\mathrm{L}_{3,2}$ edge $(708 \mathrm{eV})$, and $\mathrm{Mg}-\mathrm{K}$ edge $(1305 \mathrm{eV})$. The concentration profiles were obtained after careful reduction of noise within the spectrum images using principal component analysis and the curve fitting procedure in order to separate the $\mathrm{Cr}_{-}-\mathrm{L}_{3,2}$ edge at 575 and the O-K edge at $530 \mathrm{eV}$ [16]. The EELS concentration profiles indicated a comparable Fe concentration within the defect and the olivine host. However, the interfaces with the olivine crystals were richer in iron over several atomic planes. This was accompanied by a slight depletion of $\mathrm{Mg}$ as compared to the olivine composition. Most significantly, the platelets were rich in Cr. STEM-EDX analysis also showed the presence of $\mathrm{Al}$ and revealed that the relative concentration of cations $(\mathrm{Cr}, \mathrm{Al}, \mathrm{Mg}, \mathrm{Fe})$ was found variable from one platelet to another. Therefore, their chemical composition could be considered as a solid solution between magnetite $\left(\mathrm{Fe}_{3} \mathrm{O}_{4}\right)$, chromite $\left(\mathrm{FeCr}_{2} \mathrm{O}_{4}\right)$, and $\mathrm{MgAl}_{2} \mathrm{O}_{4}$.
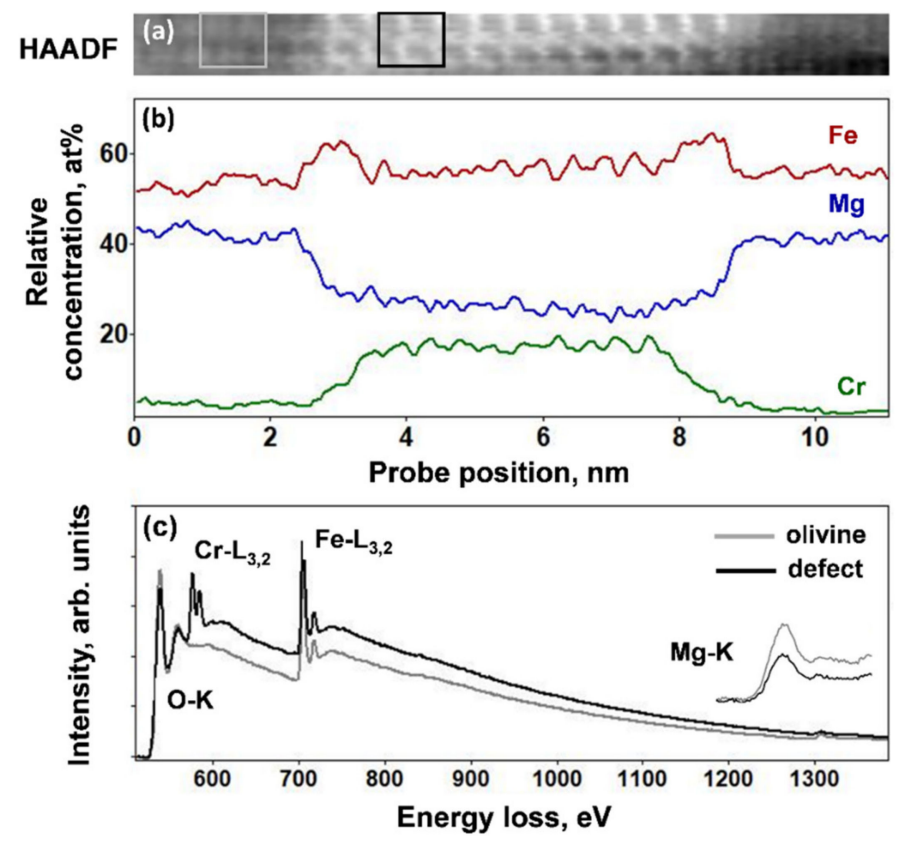

Figure 3. (a) Online HAADF image of the thick (100) platelets comparable to the one shown in Figure 2a. (b) Relative concentration profiles obtained after curve fitting of the Fe-L3,2 (red), Cr-L3,2 (green), and the Mg-K (blue) electron energy loss spectroscopy (EELS) edges. The profiles show that the platelet is $\mathrm{Cr}$ enriched and $\mathrm{Mg}$ depleted. The Fe concentration is slightly higher at two/three atomic planes at the interfaces, with respect to the olivine. There is a slight depletion of $\mathrm{Mg}$ compared to the olivine. The platelet is Cr enriched. (c) EELS spectra from the platelet and the olivine in the energy range between 500 and $1400 \mathrm{eV}$, where the O-K, Cr-L3,2, Fe-L3,2, and Mg-K EELS edges appear. The spectra were integrated over 180 pixels and extracted from the corresponding spectrum image from the places indicated by the boxes marked in (a). Gray box in (a) and gray line in (c) correspond to olivine and the black ones to the defect. In the inset of (c), a magnification on the Mg-K edge in between 1280 and $1340 \mathrm{eV}$ is given. 
Figure 4a-c shows an online HAADF image of the thinner (100) planar defect, and the corresponding relative concentration profiles of the $\mathrm{Mg}-\mathrm{K}$ edge and $\mathrm{Fe}-\mathrm{L}_{3,2}$ edges, together with the EELS spectra in the energy range between 500 and $1400 \mathrm{eV}$ for the olivine and the defect. The EELS profiles clearly show an increase of the Fe concentration accompanied by a decrease in the $\mathrm{Mg}$ content. These concentration modifications concern a 2-nm-thick area and they are highest within a peak region with $0.75 \mathrm{~nm}$ width. The $\mathrm{Fe}$ and $\mathrm{Mg}$ ratio in the olivine, expressed as $\mathrm{Fe} / \Sigma(\mathrm{Fe}+\mathrm{Mg})$, was approximately 0.58 , while it corresponded to 0.74 within the four atomic planes of the thin defect. This was in good agreement with the increase in HAADF intensity within the 2-4 atomic planes of the defect. Chromium, present in abundance in the thick platelets, was not detected in the thin planar defects.

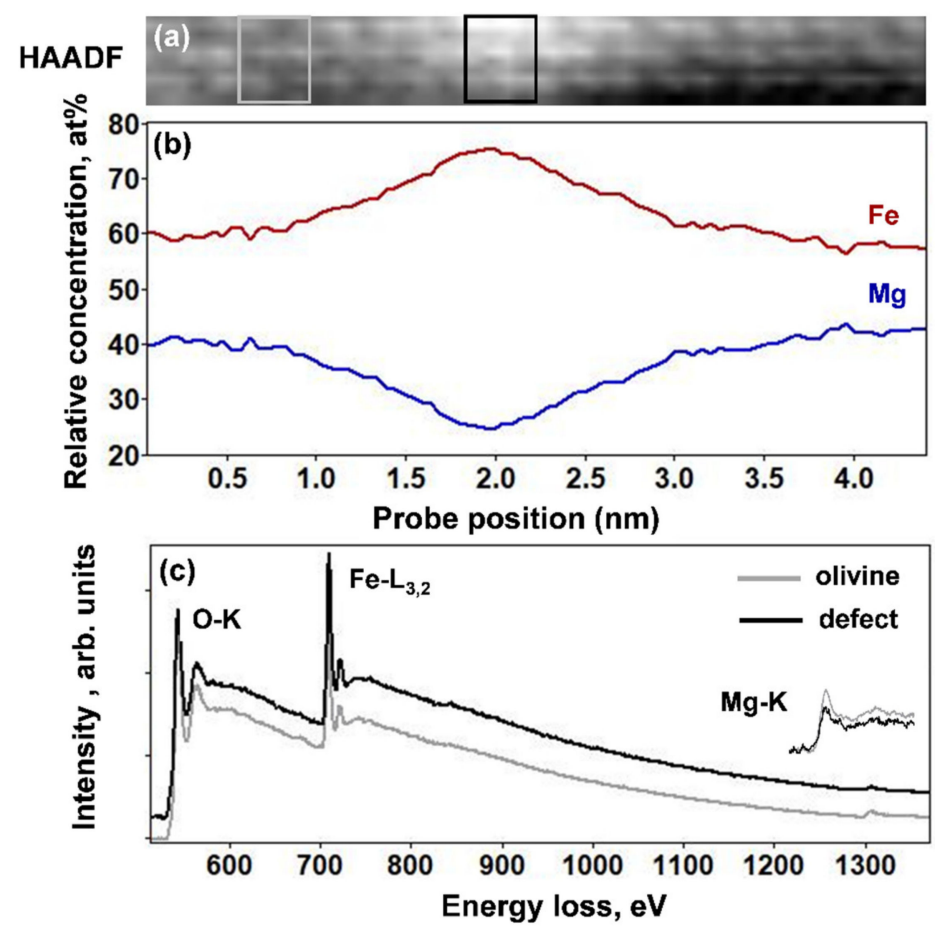

Figure 4. (a) Online HAADF image of thin (100) planar defect, comparable to the one shown in Figure 2b. (b) Relative concentration profiles of the Fe-L3,2 and Mg-K EELS edges. The EELS profiles show that this defect is enriched in Fe and depleted in Mg. (c) EELS spectra in the energy range between 500 and $1400 \mathrm{eV}$, where the $\mathrm{O}-\mathrm{K}, \mathrm{Fe}-\mathrm{L} 3,2$, and $\mathrm{Mg}-\mathrm{K}$ edges appear. The spectra were integrated over 60 pixels and extracted from the corresponding spectrum image from the places indicated by the boxes marked in (a). Gray box in (a) and gray line in (c) correspond to olivine and the black ones to the defect. In the inset of (c) a magnification on the Mg-K edge in between 1280 and $1340 \mathrm{eV}$ is given.

In order to understand the electronic structure of the defects, we looked more closely into the electron energy loss near edge structure (ELNES) at the Fe- $\mathrm{L}_{3,2}$ edge as given in Figure 5. The fine structures revealed a shift towards higher energies of $\mathrm{Fe}-\mathrm{L}_{3,2}$ and thus a change in the $\mathrm{Fe}$ oxidation state. In olivine, iron is in the $\mathrm{Fe}^{2+}$ valence state (black line) and this is accompanied by a shift towards the $\mathrm{Fe}^{3+}$ state within the atomic planes of the thinner (100) planar defect (green line). A small $\mathrm{Fe}^{3+}$ contribution was also seen within the platelets with spinel structure (red line). The ELNES spectra for both features were fitted with typical reference spectra for $\mathrm{Fe}^{2+}$ and $\mathrm{Fe}^{3+}$ oxidation states as a linear combination of individual components in order to quantify locally, within the defects, the mixed Fe oxidation state $[17,18]$. The olivine matrix was used as a $\mathrm{Fe}^{2+}$ reference (black line) and hematite $\left(\mathrm{Fe}_{2} \mathrm{O}_{3}\right)$ crystals for a reference spectrum of the $\mathrm{Fe}^{3+}$ oxidation state (blue line). Using this fitting procedure, we obtained the spectral contributions of the two references for the fitted spectrum and thereby we determined, for the $\mathrm{Cr}$-rich platelets, the $\mathrm{Fe}^{3+} / \Sigma \mathrm{Fe}$ 
ratio of the order of 0.16 . The cationic concentration profiles discussed in Figure $3 \mathrm{~b}$ reveal that within these platelets with spinel structure the Fe and $\mathrm{Cr}$ relative concentration did not correspond to the nominal stoichiometry of chromite $\left(\mathrm{FeCr}_{2} \mathrm{O}_{4}\right)$ and the composition of these platelets could be expressed as a solid solution between magnetite $\left(\mathrm{Fe}_{3} \mathrm{O}_{4}\right)$, chromite $\left(\mathrm{FeCr}_{2} \mathrm{O}_{4}\right)$, and $\mathrm{MgAl}_{2} \mathrm{O}_{4}$. Indeed, for magnetite Fe could be both divalent and trivalent, while in chromite Fe is only in $2+$ oxidation state, and in the octahedral coordination and $\mathrm{Cr}$ alone is in a 3+ oxidation state. It could rest both in octahedral and tetrahedral sites. The higher Fe concentration and the ELNES data suggested that the tetrahedral sites within the spinel platelets were shared between the $\mathrm{Cr}^{3+}$ cations, about $16 \%$ of the Fe cations (those in $\mathrm{Fe}^{3+}$ oxidation state), and the small amount of $\mathrm{Al}^{3+}$. The presence of $\mathrm{Cr}$ and $\mathrm{Al}$ in these thick platelets is probably the consequence of the precipitation of these elements initially solubilized in olivine. For the thinner Fe-rich planar defect, we obtained a higher $\mathrm{Fe}^{3+} / \Sigma \mathrm{Fe}$ ratio of the order of 0.31 . The reference spectra in Figure 5 for both the olivine matrix and the hematite were plotted with their respective spectral contributions deduced from the best fit of the experimental spectra for the thin defect. This suggests that the augmentation of the Fe concentration in the thin planar defects was accompanied by a change in the oxidation state towards $\mathrm{Fe}^{3+}$ for up to approximately $30 \%$ of the iron.

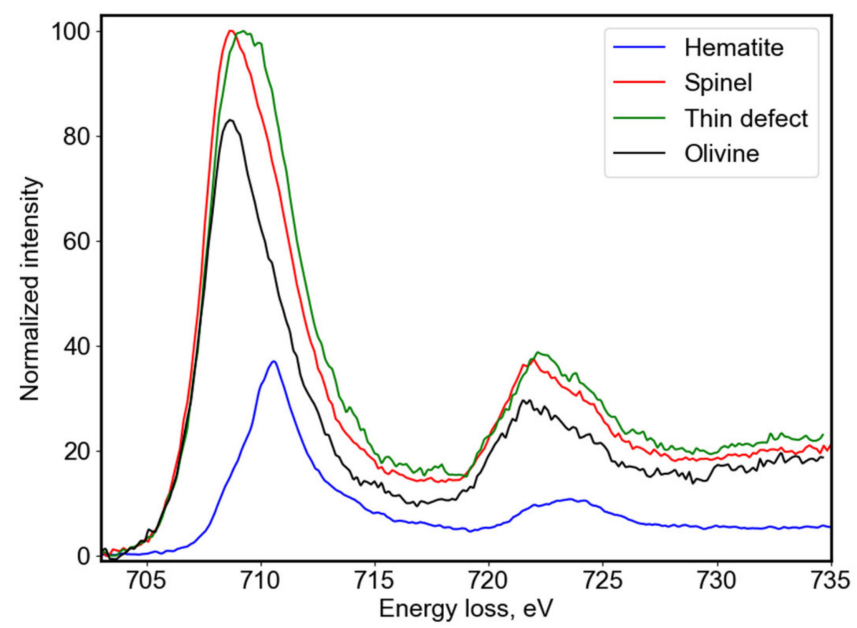

Figure 5. The energy loss near edge structures (ELNES) spectra at Fe- $\mathrm{L}_{3,2}$ edge for the thin planar defect (green line), the thicker platelet with spinel structure (red line), the olivine matrix (black line), and a reference spectrum for hematite (blue line). In order to provide direct comparison, the spectra were extracted from spectrum images with a size of 172 per 5 px containing both host olivine and the two types of defects. The presented spectra are a sum of $28 \mathrm{px}$ for the thick spinel platelet (red line) and the olivine matrix (black line) and 20 px for the thin planar defect (green line). These ELNES structures reveal a slight change of the Fe oxidation state within both features, the platelet with the spinel structure, and the thin planar defect. The olivine iron is in $\mathrm{Fe}^{2+}$ oxidation state and it becomes slightly $\mathrm{Fe}^{3+}$ within the thicker spinel platelet. The change to $\mathrm{Fe}^{3+}$ is more strongly pronounced in the thin planar defects. For hematite, Fe is in trivalent oxidation state. The ELNES spectra for the olivine and hematite were used to obtain the $\mathrm{Fe}^{3+} / \Sigma \mathrm{Fe}$ ratio for both features. These reference spectra are plotted with their corresponding spectral contributions needed to obtain the best fit for the thin planar defect.

\section{Discussion and Conclusions}

The fine-grained matrix material in primitive chondrites is recurrently a matter of debate. This matrix originates from the accretion of dust of the protoplanetary disk, but later events may induce their modification on parent bodies. In the case of CV chondrites, the matrix contains abundant Fe-rich olivine. This contrasts sharply with the mineralogy of the matrix in most primitive chondrites, which are mainly composed of amorphous silicates with a composition close to the solar composition [19-21]. To explain the presence of Fe-rich olivine in the CV chondrites, three scenarios were proposed. These include: 
(1) The formation by condensation in a nebular context, i.e., before the formation of the parent bodies [1,2]; (2) a direct formation in an aqueous environment by the metasomatism process [4]; and (3) an indirect formation through dehydration of phyllosilicates during thermal metamorphism [3,7]. This debate is not definitively closed, but the scenario involving metasomatism appears to be the most robust one. Indeed, thermochemical modeling showed that ferroan olivine could form at very moderate temperatures (100$200^{\circ} \mathrm{C}$ ) in aqueous environments [22,23]. In addition, TEM studies revealed the presence of nano-sized inclusions of organic matter and sulfides in these olivine grains [7-9]. These inclusions could hardly be explained by a high temperature formation. Finally, it is now well established that CV chondrites have undergone aqueous alteration followed by thermal metamorphism. All these elements tend to favor formation on the parent body by a secondary process.

Planar defects in olivine are not frequent but several occurrences have been reported in different contexts. For instance, it has been proposed that they could play a role in the olivine-ringwoodite transformation at high pressure [24,25]. Several occurrences of planar defects were also reported in mantle olivine and were interpreted as linked to the segregation of iron oxides or OH-bearing defects parallel to the (001) and (100) planes of olivine, under oxidizing or hydrous conditions, respectively [26-30]. Experimental works were carried out with Fe-rich olivine under oxidizing conditions [31]. These studies showed that Fe-oxides are produced as extended thin planar defects or needles with a topotactic relationship with the olivine matrix. In olivine from the matrix of CV3 chondrites, planar defects have been reported by several authors [8,10-12]. Tomeoka and Buseck [12] suggested that oxidizing conditions could have been the cause of the formation of the (100) lamellae in olivine.

Our EELS results confirm the interpretation by Tomeoka and Buseck [12]. The characterization at the atomic scale of the defects showed that they contained a significant amount of $\mathrm{Fe}^{3+}\left(\mathrm{Fe}^{3+} / \Sigma \mathrm{Fe}=0.31\right.$, Figure 5). For high oxygen fugacity, olivine is no longer stable because iron tends to become trivalent. The formation of $\mathrm{Fe}^{3+}$ is associated with that of vacancies on octahedral sites in order to preserve the electroneutrality of the crystal network [32]. If the temperature is sufficient to allow atomic mobility, the Fe trivalent cations segregate and contribute to the exsolution lamellae growth. When the lamellae became thicker, they adopted a spinel-like structure with epitaxial relationships with the host olivine. Both structures share their hexagonal close packing of oxygen ions according to the structural relationships $(100)_{\mathrm{ol}} / /(111)_{\mathrm{sp}}$. When the planar defects were very thin, our high-resolution HAADF study showed that their structure was close to that of olivine, but with small lattice distortions. In this case, olivine imposed the crystallographic structure of the exsolution layer. The distortions which were observed in the HAADF images concerned to the largest extent the mixed atomic columns with tetrahedral Si cations and Fe/Mg cations in the M2 octahedral position. Therefore, we believe that they could be explained by substitution of $\mathrm{Fe}^{3+}$ in the place of $\mathrm{Si}^{4+}$ in the tetrahedral sites. Indeed, for spinel, the $\mathrm{M}_{\mathrm{T}}-\mathrm{O}$ distances, where $\mathrm{M}_{\mathrm{T}}$ signifies cations in tetrahedral positions, are smaller for $\mathrm{Si}^{4+}$ as compared to $\mathrm{Fe}^{3+}$ cations by about 25 to $35 \mathrm{pm}$. The reported cation-anion distances for the octahedral sites are in a similar manner larger by about 20 to $30 \mathrm{pm}$ for both divalent and trivalent Fe as compared to Si cations [33]. Moreover, for olivine, both Si tetrahedra and metal octahedra are distorted, where these distortions and the length of cation-anion bonds could be different depending on the chemical nature and the oxidation state of the cation. The differential lengthening of the $\mathrm{Si}-\mathrm{O}$ and/or $\mathrm{Fe}-\mathrm{O}$ bonds is related to cation repulsion [34]. This could explain the measured alternative lengthening and shortening, by up to $20 \mathrm{pm}$, of the doublet structures in our HAADF images (Figure 2e) containing atomic columns with Si cations, when those tetravalent cations were replaced by $\mathrm{Fe}^{3+}$ ones within the tetrahedra. In order to preserve the charge balance within these $\mathrm{Fe}^{3+}$-rich thin defects, a change of the valence state to $\mathrm{Fe}^{3+}$ of a nearby $\mathrm{Fe}^{2+}$ in octahedral sites or a substitution of divalent $\mathrm{Mg}$ cations by ferric iron should simultaneously take place. The decrease of $\mathrm{Mg}$ relative concentration by approximately $15 \%$, as seen in Figure $4 \mathrm{~b}$, agreed with this 
substitution scheme. This substitution reaction is comparable to the formation of ferriTschermak's molecule in clinopyroxenes, where two trivalent iron cations substitute one $\mathrm{Si}^{4+}$ and one $\mathrm{Mg}^{2+}$ cation [35]. The thin planar defects observed in high-resolution HAADF images in Figure $2 b$ therefore should represent an intermediate arrangement between the olivine and spinel structures, where $\mathrm{Fe}^{3+}-\mathrm{Si}^{4+}$ and $\mathrm{Fe}^{3+}-\mathrm{Mg}^{2+}$ substitutions take place, but the structural transformation to a spinel structure is yet limited by the crystallographic constrains imposed by the olivine. This configuration is close to the Guinier-Preston zones, which involve the early stage of precipitation, frequently encountered in metals and in some silicates like pyroxene for instance [36]. The extended thin planar defects in the Allende olivine are essentially distorted region of the matrix, enriched in $\mathrm{Fe}^{3+}$, but not lamellae, which express a different lattice. These planar defects are metastable and finally convert into the spinel structure when they become thicker than a few unit cells.

The Allende chondrite is part of the CV3 oxidized subgroup [37]. The matrix of Allende has been significantly transformed on the CV3 parent body, leading to a wide range of secondary minerals. Fe-rich olivine is the main secondary mineral in the Allende matrix [38]. Our study showed that olivine underwent an episode of oxidation as attested by the presence of thin planner defects rich in $\mathrm{Fe}^{3+}$. The Al-Cr-rich platelets also contained $\mathrm{Fe}^{+3}$ but in lower concentration. The exsolution formation required first a change of iron valence state, followed by thermoactivated diffusion and substitution of $\mathrm{Si}^{4+}$ by $\mathrm{Fe}^{3+}$. This level of oxidation is not compatible with a nebular, pre-accretional formation of olivine because of the too-low partial pressure of oxygen. For this reason, it is likely that the exsolution lamellae (thin planar defects and platelet) developed within the parent body during the metamorphic stage. In CV3, due to the complexity of the mineralogy in the matrices, the peak temperature associated with the metamorphic episode of the parent body is not well constrained. Estimates of the peak temperature range from $330-600{ }^{\circ} \mathrm{C}$ depending on the markers used (see review in [39]). The $\mathrm{Fe}^{3+}$-rich planar defects should make it possible to better constrain the metamorphic peak temperature. However, the Si diffusion coefficients depend on many parameters (oxygen fugacity, $\mathrm{FeO}$ content in olivine, presence of $\mathrm{OH}$ type defects) and the published values show strong variations depending on the experimental conditions (see review in [40]). Moreover, there are no experimental data in the temperature range $300-600{ }^{\circ} \mathrm{C}$. Using the average values for diffusion of $\mathrm{Si}$ recommended by Zhang and Shan [40] at atmospheric pressure and extrapolating them to moderate temperatures and a metamorphic event $1 \times 10^{6} \mathrm{yrs}$, the diffusion distance $x=2 \sqrt{D t}$ was of the order of $0.1 \mathrm{~nm}$ at $500{ }^{\circ} \mathrm{C}$ and of a few nanometers at $600{ }^{\circ} \mathrm{C}$. This calculation must be taken with caution for the reasons mentioned above, but it is well compatible with the temperature range of the metamorphic peak temperature of Allende.

Author Contributions: Conceptualization, P.C., M.M., and H.L.; methodology, M.M., P.C., and D.J.; validation, M.M., H.L., P.C., A.G., and D.J.; TEM experiments, A.G., M.M., and P.C.; writing—original draft preparation, M.M. and H.L.; writing—review and editing, P.C., A.G., and D.J.; supervision, H.L. All authors have read and agreed to the published version of the manuscript.

Funding: The authors thank the Chevreul Institute (FR 2638) for its help in the development of this work. Chevreul Institute and the TEM facility in Lille is supported by the "Ministère de l'Enseignement Supérieur et de la Recherche », the Conseil Regional du Nord-Pas de Calais and the European Regional Development Fund (ERDF). The authors acknowledge support from the CNRS-CEA "METSA" microscopy French network for the STEM-EELS experiments. They also thank the ISITE ULNE (Université Lille Nord Europe) and the MEL (Métropole Européenne de Lille).

Institutional Review Board Statement: Not applicable.

Informed Consent Statement: Not applicable.

Data Availability Statement: The data presented in this study are available on request from the corresponding author.

Acknowledgments: The authors thank D. Troadec from the Institut d'Électronique de Microélectronique et de Nanotechnologie (IEMN), University of Lille, for the preparation of high-quality FIB sections. We thank the three anonymous reviewers for their careful reading of our manuscript and their in- 
sightful comments and suggestions which helped us to improve the quality and the presentation of the manuscript.

Conflicts of Interest: The authors declare no conflict of interest.

\section{References}

1. Weisberg, M.K.; Prinz, M. Fayalitic olivine in CV3 chondrite matrix and dark inclusions: A nebular origin. Meteorit. Planet. Sci. 1998, 33, 1087-1099. [CrossRef]

2. Palme, H.; Fegley, B. High-temperature condensation of iron-rich olivine in the solar nebula. Earth Planet. Sci. Lett. 1990, 101, 180-195. [CrossRef]

3. Kojima, T.; Tomeoka, K. Indicators of aqueous alteration and thermal metamorphism on the CV parent body: Microtextures of a dark inclusion from Allende. Geochim. Cosmochim. Acta 1996, 60, 2651-2666. [CrossRef]

4. Krot, A.N.; Petaev, M.I.; Bland, P.A. Multiple formation mechanisms of ferrous olivine in CV carbonaceous chondrites during fluid-assisted metamorphism. Antarct. Meteor. Res. 2004, 17, 154-172.

5. Watt, L.E.; Bland, P.A.; Prior, D.J.; Russell, S.S. Fabric analysis of Allende matrix using EBSD. Meteorit. Planet. Sci. 2006, 41, 989-1001. [CrossRef]

6. Bland, P.A.; Howard, L.E.; Prior, D.J.; Wheeler, J.; Hough, R.M.; Dyl, K.A. Earliest rock fabric formed in the Solar System preserved in a chondrule rim. Nat. Geosci. 2011, 4, 244-247. [CrossRef]

7. Brearley, A.J. Origin of graphitic carbon and pentlandite in matrix olivines in the Allende meteorite. Science 1999, 280, 1380-1382. [CrossRef]

8. Abreu, N.M.; Brearley, A.J. Deciphering the nebular and asteroidal record of silicates and organic material in the matrix of the reduced CV3 chondrite Vigarano. Meteorit. Planet. Sci. 2011, 46, 252-274. [CrossRef]

9. Cuvillier, P.; Leroux, H.; Jacob, D.; Hirel, P. Fe-Mg interdiffusion profiles in rimmed forsterite grains in the Allende matrix: Time-temperature constraints for the parent body metamorphism. Meteorit. Planet. Sci. 2015, 50, 1529-1545. [CrossRef]

10. Keller, L.P.; Buseck, P.R. Aqueous alteration in the Kaba CV3 carbonaceous chondrite. Geochim. Cosmochim. Acta 1990, 54, 2113-2120. [CrossRef]

11. Keller, L.P.; Thomas, K.L.; Clayton, R.N.; Mayeda, T.K.; DeHart, J.M.; McKay, D.S. Aqueous alteration of the Bali CV3 chondrite: Evidence from mineralogy, mineral chemistry, and oxygen isotopic compositions. Geochim. Cosmochim. Acta 1994, 58, 5589-5598. [CrossRef]

12. Tomeoka, K.; Buseck, P.R. Phyllosilicates in the Mokoia CV carbonaceous chondrite: Evidence for aqueous alteration in an oxidizing environment. Geochim. Cosmochim. Acta 1990, 54, 1745-1754. [CrossRef]

13. Lee, M.R.; Hutchison, R.; Graham, A.L. Aqueous alteration in the matrix of the Vigarano (CV3) carbonaceous chondrite. Meteorit. Planet. Sci. 1996, 31, 477-483. [CrossRef]

14. Noguchi, T.; Ishikawa, K.; Ninagawa, K. Effects of terrestrial weathering on the matrix mineralogy of colony $\mathrm{CO}_{3}$ chondrite. Antarct. Meteor. Res. 1999, 12, 36-56.

15. Sung, C.-M.; Burns, R.G. Crystal structural features of the olivine $\rightarrow$ spinel transition. Phys. Chem. Miner. 1978, 2, 177-197. [CrossRef]

16. De la Peña, F.; Prestat, E.; Fauske, V.T.; Burdet, P.; Furnival, T.; Jokubauskas, P.; Nord, M.; Ostasevicius, T.; MacArthur, K.E.; Johnstone, D.N.; et al. HyperSpy 1.6.1; Zenodo, CERN: Meyrin, Switzerland, 2020. [CrossRef]

17. Chen, S.-Y.; Gloter, A.; Zobelli, A.; Wang, L.; Chen, C.-H.; Colliex, C. Electron energy loss spectroscopy and ab initio investigation of iron oxide nanomaterials grown by a hydrothermal process. Phys. Rev. B 2009, 79, 104103. [CrossRef]

18. Van Aken, P.A.; Liebscher, B. Quantification of ferrous/ferric ratios in minerals: New evaluation schemes of Fe L23electron energy-loss near-edge spectra. Phys. Chem. Miner. 2002, 29, 188-200. [CrossRef]

19. Brearley, A.J. Matrix and fine-grained rims in the unequilibrated $\mathrm{CO}_{3}$ chondrite, ALHA77307: Origins and evidence for diverse, primitive nebular dust components. Geochim. Cosmochim. Acta 1993, 57, 1521-1550. [CrossRef]

20. Le Guillou, C.; Brearley, A. Relationships between organics, water and early stages of aqueous alteration in the pristine CR3.0 chondrite MET 00426. Geochim. Cosmochim. Acta 2014, 131, 344-367. [CrossRef]

21. Leroux, H.; Cuvillier, P.; Zanda, B.; Hewins, R.H. GEMS-like material in the matrix of the Paris meteorite and the early stages of alteration of CM chondrites. Geochim. Cosmochim. Acta 2015, 170, 247-265. [CrossRef]

22. Zolotov, M.Y.; Mironenko, M.V.; Shock, E.L. Thermodynamic constraints on fayalite formation on parent bodies of chondrites. Meteorit. Planet. Sci. 2006, 41, 1775-1796. [CrossRef]

23. Jogo, K.; Nakamura, T.; Noguchi, T.; Zolotov, M.Y. Fayalite in the Vigarano CV3 carbonaceous chondrite: Occurrences, formation age and conditions. Earth Planet. Sci. Lett. 2009, 287, 320-328. [CrossRef]

24. Kerschhofer, L.; Rubie, D.C.; Sharp, T.G.; McConnell, J.D.C.; Dupas-Bruzek, C. Kinetics of intracrystalline olivine-ringwoodite transformation. Phys. Earth Planet. Inter. 2000, 121, 59-76. [CrossRef]

25. Chen, M.; Goresy, A.E.; Gillet, P. Ringwoodite lamellae in olivine: Clues to olivine-ringwoodite phase transition mechanisms in shocked meteorites and subducting slabs. Proc. Natl. Acad. Sci. USA 2004, 101, 15033-15037. [CrossRef] [PubMed]

26. Kitamura, M.; Kondoh, S.; Morimoto, N.; Miller, G.H.; Rossman, G.R.; Putnis, A. Planar OH-bearing defects in mantle olivine. Nature 1987, 328, 143-145. [CrossRef] 
27. Banfield, J.F.; Veblen, D.R.; Jones, B.F. Transmission electron microscopy of subsolidus oxidation and weathering of olivine. Contrib. Mineral. Petrol. 1990, 106, 110-123. [CrossRef]

28. Banfield, J.F.; Dyar, M.D.; McGuire, A.V. The defect microstructure of oxidized mantle olivine from Dish Hill, California. Am. Mineral. 1992, 77, 977-986.

29. Khisina, N.R.; Wirth, R.; Andrut, M.; Ukhanov, A.V. Extrinsic and intrinsic mode of hydrogen occurrence in natural olivines: FTIR and TEM investigation. Phys. Chem. Miner. 2001, 28, 291-301. [CrossRef]

30. Khisina, N.; Wirth, R.; Matsyuk, S.; Koch-Müller, M. Microstructures and OH-bearing nano-inclusions in. Eur. J. Mineral. 2008, 1067-1078. [CrossRef]

31. Champness, P.E. Nucleation and growth of iron oxides in olivines, (Mg,Fe) ${ }_{2} \mathrm{SiO}_{4}$. Mineral. Mag. 1970, 37, 790-800. [CrossRef]

32. Buening, D.K.; Buseck, P.R. Fe-Mg lattice diffusion in olivine. J. Geophys. Res. 1973, 78, 6852-6862. [CrossRef]

33. Hazen, R.M.; Yang, H. Effects of cation substitution and order-disorder on P-V-T equations of state of cubic spinels. Am. Mineral. 1999, 84, 1956-1960. [CrossRef]

34. Birle, J.D.; Gibbs, G.V.; Moore, P.B.; Smith, J.V. Crystal structures of natural olivines. Am. Mineral. 1968, 53, 807-824.

35. Redhammer, G.J. Mössbauer spectroscopy and Rietveld refinement on synthetic ferri-Tschermak's molecule CaFe ${ }^{3+}\left(\mathrm{Fe}^{3+} \mathrm{Si}\right) \mathrm{O}_{6}$ substituted diopside. Eur. J. Mineral. 1998, 10, 439-452. [CrossRef]

36. Xu, H.; Shen, Z.; Konishi, H.; Luo, G. Crystal structure of Guinier-Preston zones in orthopyroxene: Z-contrast imaging and ab initio study. Am. Mineral. 2014, 99, 2043-2048. [CrossRef]

37. Mcsween, H.Y. Petrographic variations among carbonaceous chondrites of the Vigarano type. Geochim. Cosmochim. Acta 1977, 41, 1777-1790. [CrossRef]

38. Krot, A.N.; Petaev, M.I.; Zolensky, M.E.; Keil, K.; Scott, E.R.D.; Nakamura, K. Secondary calcium-iron-rich minerals in the Bali-like and Allende-like oxidized CV3 chondrites and Allende dark inclusions. Meteorit. Planet. Sci. 1998, 33, 623-645. [CrossRef]

39. Ganino, C.; Libourel, G. Reduced and unstratified crust in CV chondrite parent body. Nat. Commun. 2017, 8, 1-10. [CrossRef]

40. Zhang, B.; Shan, S. Application of the $\mathrm{cB} \Omega$ model to the calculation of diffusion parameters of Si in silicates. Geochem. Geophys. Geosyst. 2015, 16, 705-718. [CrossRef] 